\title{
Optimization of osmotic dehydration of yellow carrot slices using response surface methodology
}

\author{
- Sucheta ${ }^{1 *}$, Kartikey Chaturvedi², Simran Arora ${ }^{1}$ and Rakesh Gehlot ${ }^{1}$ \\ ${ }^{1}$ Centre of Food Science and Technology, C.C.S. Haryana Agricultural University, Hisar (Haryana) India \\ ${ }^{2}$ National Institute of Food Technology Entrepreneurship and Management, Sonepat (Haryana) India \\ Email : suchetakkr@gmail.com
}

*Author for Correspondence

Research chronicle : Received : 13.04.2018; Revised : 19.05.2018; Accepted : 27.05.2018

\begin{abstract}
SUMMARY :
Response surface methodology is typically used for mapping a response surface over a particular region of interest, optimizing the response or for selecting operating conditions to achieve target specifications. The present investigation aimed to optimize the time, temperature and sucrose concentration for osmo-dehydration of carrots slices to maximize water loss, solute gain, dehydration efficiency, minimum water activity and texture values. The experimental design was found to be significant in terms of p-values less than 0.0500 . Numerical optimization showed that $37.53^{\circ} \mathrm{C}$ temperature, 6.9 hours time, $61.6{ }^{\circ} \mathrm{B}$ sucrose concentration gives the best responses as 66 per cent water loss, 16.8 per cent solute gain, $3.8 \mathrm{DE}, 0.49 \mathrm{aW}$ and $44.40 \mathrm{~N}$ texture.

KEY WORDS : RSM, Yellow carrots slices, Water loss, Solute gain, Water activity, Texture

How to cite this paper: Sucheta, Chaturvedi, Kartyikey, Arora, Simran and Gehlot, Rakesh (2018). Optimization of osmotic dehydration of yellow carrot slices using response surface methodology. Internat. J. Proc. \& Post Harvest Technol., 9 (1) : 28-33. DOI: 10.15740/HAS/IJPPHT/9.1/28-33. Copyright@ 2018: Hind AgriHorticultural Society.
\end{abstract}

